\title{
Breves notas sobre o medo e o mundo como "nave"
}

\author{
ALBERTO LUIZ DE ANDRADE NETO \\ Universidade Federal de Santa Catarina, Florianópolis, Santa Catarina, Brasil \\ alberto_andrade_neto@hotmail.com
}

DOI 10.11606/issn.2316-9133.v29isuplp310-318

resumo No contexto da pandemia da COVID-19, os medos urgem e ressaltam ainda mais as desigualdades históricas e estruturais. Este ensaio trata, a partir de uma proposta artística de Rivane Neuenschwander, dos medos e os coloca em uma direção relacional que aponta para as vulnerabilidades e as precariedades que também constituem tais afetos. Diante disso, argumento que os modelos que valorizam um hiperindivíduo não contribuem para políticas de eficiência em tempos pandêmicos. Por fim, tomo as ontologias indígenas como um caminho de renovação frente ao modelo ocidental que insiste em produzir indivíduos separados do mundo.

palavras-chave COVID-19. Medo. Vulnerabilidade.

\section{Brief notes about fear and the world as a spaceship}

abstract In the context of the COVID-19 pandemic, fears are urgent and further emphasize historical and structural inequalities. From an artistic proposal by Rivane Neuenschwander, this essay deals with fears and puts them in a relational direction pointing to the vulnerabilities and precariousness that also constitute such affects. I argue that models which value a hyper individuality does not contribute to efficiency policies in pandemic times. Finally, I return to indigenous ontologies as a path of renovation in the face of this Western model that insists on producing individuals apart from the world.

keywords COVID-19. Fear. Vulnerability.

\section{Breves notas sobre el miedo y el mundo como una nave}

resumen En el contexto de la pandemia del COVID-19, los temores son urgentes y ponen aún más de relieve las desigualdades históricas y estructurales. Este ensayo, basado en una propuesta artística de Rivane Neuenschwander, trata de los miedos y los sitúa en una dirección relacional que apunta a las vulnerabilidades y precariedades que también constituyen tales afectos. En vista de ello, el articulo sostiene que los modelos que valoran a un hiperindividuo no contribuyen a las políticas de eficiencia en tiempos de pandemia. Por 
último, tomo las ontologías indígenas como un camino de renovación en relación con el modelo occidental que insiste en producir individuos separados del mundo.

palabras clave COVID-19. Miedo. Vulnerabilidad

\section{Introdução'}

cantaremos o medo dos ditadores, o medo dos democratas, cantaremos o medo da morte e o medo de depois da morte.

Carlos Drummond de Andrade

Nesses aflitivos dias de quarentena recorro aos livros da estante, abro um deles e vejo uma lista de medos nomeados por crianças. Seleciono alguns: acidente, acontecerem coisas ruins, Annabelle, aranha de 10 cabeças, bala perdida, bomba, cirurgia, de alguma pessoa da minha família que eu amo morrer, de eu não encontrar meus melhores amigos, de eu não ter emprego e morar na rua, diabo, dor, esquecer, estuprador, família morrer, fim do mundo, ilusão de coisas ruins, injeção, me perder, montanha-russa, mosquito, nada, não tenho medo, onça, pânico, perder as pessoas que gosto, pesadelo de um terrível vampiro, precisar ir ao hospital, que esqueçam de mim, sair da rotina, ser atropelado, tiro, tiroteio, todos serem infectados por zumbi, um pouco de palhaço, violência, zumbi com cabeça de bacalhau babão com os olhos vesgos, entre tantos outros (LAGNADO, 2017, s/p).

\section{“O nome do medo": precariedade, vírus, arte e antropologia}

Esses medos são parte do projeto, "O nome do medo/Rio de Janeiro" (2017), proposto pela artista Rivane Neuenschwander ${ }^{2}$ (Belo Horizonte, Minas Gerais, 1967). Ele contou com uma exposição no Museu de Arte do Rio (RJ) e uma dezena de sessões de trabalho na Escola de Artes Visuais (EAV) do Parque Lage (RJ). Em síntese, as sessões foram oficinas que apresentaram - para quase 200 crianças, entre 6 a 13 anos, de escolas públicas, particulares e de redes de reinserção social - projeções de fotografias de capas (de super-heróis, por exemplo) e falas encorajando as crianças a nomearem seus medos. A partir disso, elas escreveram os nomes dos seus medos em folhas de papel, os desenharam e confeccionaram capas que poderiam ser, posteriormente, levadas para casa.

\footnotetext{
${ }^{1}$ Agradeço à Ana Valéria Salza de Vasconcelos, Érica Abreu, Julia Marques Faraco, Lino Nascimento dos Santos, Sandra Stephanie Holanda Ponte Ribeiro e Will Lucas Silva Pena pela leitura e os comentários generosos. À Rivane Neuenschwander pela atenção e por ceder a fotografia que consta nesse ensaio. À toda equipe da Revista Cadernos de Campo pelo trabalho minucioso. Por fim, e sobretudo, agradeço à Sandra Benites e a Ailton Krenak, intelectuais que incansavelmente sopram o renovo e a esperança para esses tempos tão matadores.

2 Para informações sobre Rivane Neuenschwander ver mais em: Flood, et.al., 2010; Lagnado, 2017; Pedrosa, 2014.
} 
A proposta de "O nome do medo", de 2017 e revisitada no contexto pandêmico de 2020, reforça uma destituição da centralidade do "indivíduo ocidental" do neoliberalismo, aponta para posições mais próximas das relações e recupera a dimensão social e estrutural dos afetos. Estas que são chave numa inclinação crítica sobre as medidas - inoperantes e facínoras, verdadeiras necropolíticas genocidas - encaradas pelo atual Governo brasileiro em relação à COVID-19. Aliás, continuamos sem um Ministro da Saúde.

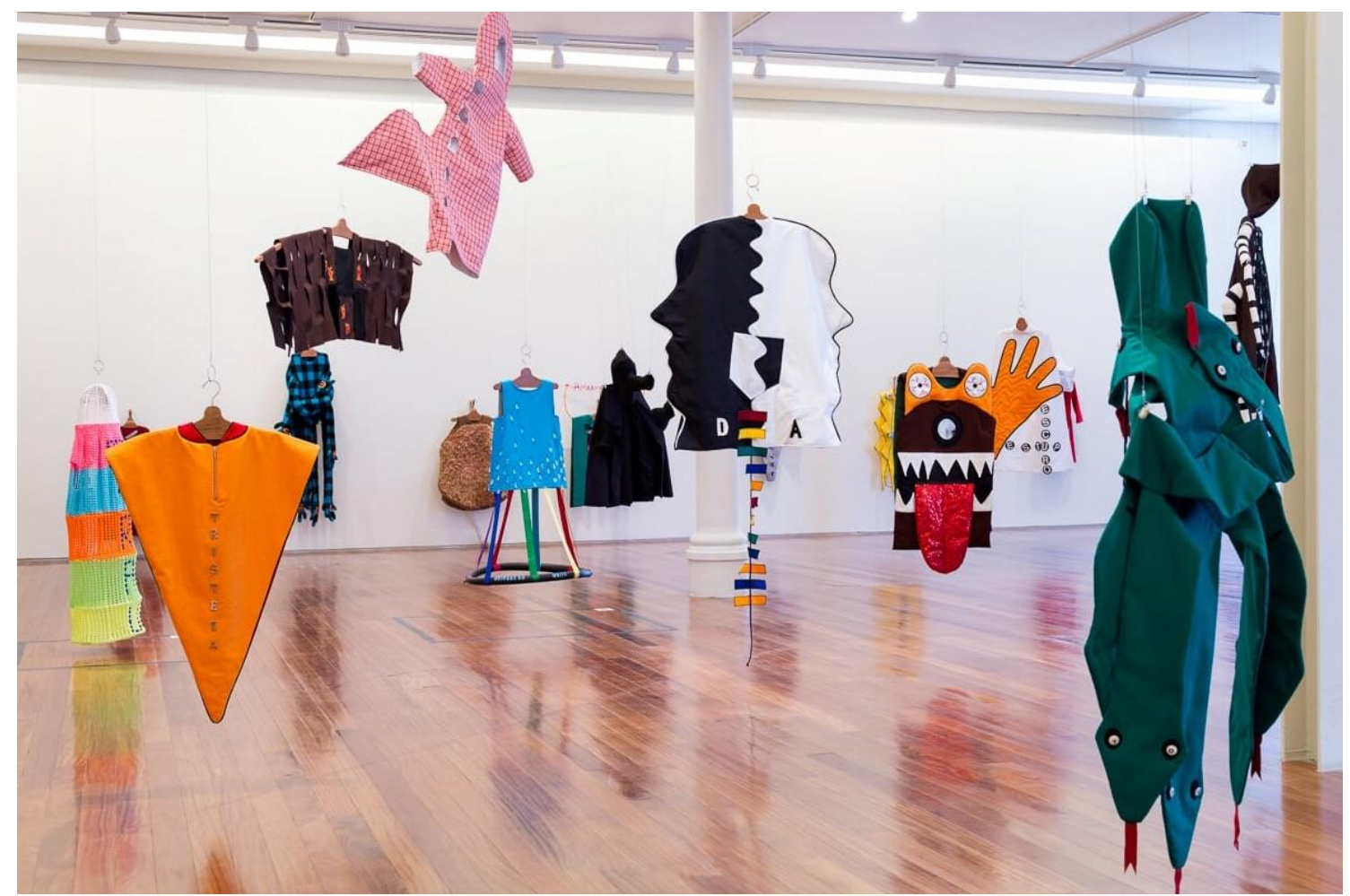

Figura 1. Vista da exposição "O nome do medo" (2017), realizada no Museu de Arte do Rio (MAR). Créditos: Fotografia de Pedro Agilson. Gentilmente cedida e selecionada por Rivane Neuenschwander.

Neuenschwander (2017) diz que as capas possuem a função dupla de "abrigos" e de "afugentarem sentimentos relacionados ao medo" (p. 22). Na dinâmica do projeto também podiam produzir abertura, leveza e ludicidade para que as crianças pudessem apresentar seus medos em um ambiente público de trocas. Em uma das etapas finais do projeto o estilista Guto Carvalhoneto, conjuntamente com o pessoal de seu ateliê, produziu capas que ganharam exposição no Museu (Ver figura 1). Os desenhos feitos pelas crianças compuseram uma base para que pudessem ser criadas essas peças de tecido que contavam com mais de um medo. Os medos eram mesclados uns nos outros, como se a artista propusesse um diálogo e uma interação entre eles, constituindo mesmo uma relacionalidade e, na sala de exposição, outras pessoas também os vestissem.

Longe de serem vistos aqui como uma anterioridade individual, sugiro tratar os medos em um campo relacional e que compreende as relações de poder, as desigualdades históricas e as sistemáticas ausências da infraestrutura do Estado. Muitas das nomeações são resultantes 
de vulnerabilidades e precariedades que acompanham populações que sempre estiveram mais próximas da morte. Não é à toa que os medos apresentados pelas crianças no Brasil incluam uma série de nomeações diferentes daqueles proferidos pelas crianças na primeira versão do "Nome do medo/Londres" (exposição realizada na Inglaterra em 2015).

Em tempos de COVID-19, os medos urgem e contrastam mais ainda as diferenças e revela as fragilidades das políticas públicas de saúde e de outros programas sociais, e reafirmam as atrocidades geradas pelo sistema capitalista, ressaltando as feridas coloniais (à maneira de Mbembe [(2018)]). Afinal, o Estado não teria alguma responsabilidade diante da experiência dos medos enunciada pelas crianças? Ou, ainda, como colocado pela própria artista: "quais os mecanismos de terror usados por um determinado governo para a manutenção do controle dentro da sociedade?" (NEUENSCHW ANDER; LAGNADO, 2017, p. 23).

Os medos descritos pelas crianças em "O nome do medo" continuam e, quiçá, ainda mais latentes. Por exemplo, mesmo com a determinação do Supremo Tribunal Federal (STF) em proibir operações policiais em favelas do Rio de Janeiro durante a pandemia, o terror perpetrado por agentes policiais nas comunidades segue fazendo vítimas. Muitas dessas são comunidades em que residem crianças que participaram de "O nome do medo". Não é à toa que "polícia" apareça seis vezes consecutivas na lista dos medos delas, além de três ocorrências para "arma"; continua com "assassino", "bala perdida”, "do cara que estava com uma metralhadora”, dentre tantas outras que reforçam esse contexto de guerra na cidade do Rio de Janeiro.

Segundo Judith Butler (2018, p. 40), “a 'precariedade' designa a situação politicamente induzida na qual determinadas populações sofrem as consequências da deterioração de redes de apoio sociais e econômicas mais do que outras". A autora continua: "e ficam diferentemente expostas ao dano, à violência e à morte" (Ibidem). Os medos nomeados pelas crianças e as precariedades que eles descrevem andam de mãos dadas, pois o acesso à água, ao saneamento básico, aos produtos de higiene pessoal, à alimentação diária, à informação, às condições dignas de trabalho, à educação, à habitação, ao transporte e ao sistema de saúde não são distribuídos de forma igualitária em um país cuja colonização produziu abismos entre diferentes populações. Falar sobre os medos demanda também entender que muitas estratégias de Estados e governos não são eficazes e não conseguem assegurar muitos dos direitos básicos previstos pela Constituição.

O modelo neoliberal, que sustenta diversas ações do governo brasileiro frente à COVID-19, e que ainda estrutura muitas governamentalidades mundiais desse século, reifica o estatuto do indivíduo em sua potência maximizada, personificando assim as medidas contra o vírus e abordando os medos unicamente em uma dimensão individual. Assim, sujeitos são disciplinados para compreenderem-se como "empresários de si mesmos", tendo seus "desejos racionalizados pela empresa capitalista", e abrindo também uma interface de controle psíquico pelo governo que obedece a um vocabulário da economia e da administração (SAFATLE, 2015). Os problemas dessa direção são as operações que não 
levam a sério as assimetrias e as desigualdades continuadas; gerando um controle governamental pelo medo e provocando uma mortandade de crescimento exponencial para as "vidas matáveis" (BUTLER, 2010).

Neste sentido, Marilyn Strathern (2014) pode corroborar com a argumentação quando me lembro de sua importante reflexão endereçada às investigações nas Ciências Sociais: "O conceito de sociedade está teoricamente obsoleto?". Tal indagação destacava os problemas que a aplicabilidade do conceito de "sociedade" como "entidade" ou "coisa" trouxera às pesquisas em Antropologia. Segundo argumenta a autora, tal direção gerou prejuízos analíticos provocando oposições, dicotomias, construindo um mundo composto por unidades e até mesmo transformando-as em entidades discretas. E, extrapolando a reflexão de Strathern, talvez, a mais nociva dessas derivações tenha sido o "indivíduo" do neoliberalismo thatcherista. Tal modelo político eliminou muitas organizações que tratavam de interesses específicos, coincidindo com as privatizações de setores que cuidavam dos serviços sociais, descartando coletividades que trabalhavam por certas reivindicações junto ao Estado e cedendo lugar ao entendimento de que sujeitos são autossuficientes financeiramente, e que possuem somente a função de produzir e consumir.

Isto retorna, por exemplo, em um dos pronunciamentos do Presidente da República, Jair Bolsonaro, ao distorcer a fala de Tedros Adhanom, atual diretor da Organização Mundial da Saúde (OMS), que então se referia à importância do Estado em promover determinações eficazes aos mais vulneráveis, optando assim por fazer um recorta, copia e cola com uma estruturação de natureza neoliberal:

\begin{abstract}
"Muitas pessoas de fato, têm que trabalhar todos os dias para ganhar seu pão diário', e que 'os governos têm que levar esta população em conta'. Continua ainda, 'se fecharmos ou limitarmos movimentações, o que vai acontecer com essas pessoas que têm de trabalhar todos os dias e que têm de ganhar o pão de cada dia todos os dias?"' (Pronunciamento oficial do dia 31 de março de 2020. Os conectivos e destaques foram utilizados pelo próprio Presidente na distorção da fala de Adhanom).
\end{abstract}

Neste caso, as "matrizes de relação" são obliteradas e cedem lugar ao hiperindividualismo que repele as responsabilidades do Estado. O contraponto ao "empresariamento de si" e todos os outros matizes neoliberais e seus conceitos absolutos, pode lançar mão da "socialidade" stratherniana que consegue recuperar as relações de volta à vida, e desfazer o entendimento de pessoas como "indivíduos extrassociais" com uma existência arrancada das relações (2014). Como se fossemos "socializados" posteriormente num arranjo maior denominado "sociedade". O erro da reificação tanto de "sociedade" quanto de "indivíduo" é exatamente a destituição das existências humanas em prol de relações isoladamente secundárias e não de interações de ordem primária. 


\section{A ontologia da pessoa indígena e a "nave": renovações para o futuro}

Entendo assim que uma das sugestões do "O nome do medo" seja a de colocar em evidência as emoções em uma dimensão estrutural. Atritar esse projeto artístico junto das atuais medidas e discursos governamentais é mais uma vez reconhecer que as políticas que destroem as relações em prol de um hiperindividualismo ("o indivíduo") não dão conta da complexidade das precariedades históricas e estruturais. A dimensão material do procedimento artístico proposto por Neuenschwander - os nomes dos medos escritos em papéis, os desenhos dessas emoções e, também, a sua confecção em tecidos e outros materiais - consegue, como um gesto e uma suspensão, devolver à vida as relações que existem nesse emaranhado vital. A materialidade do projeto artístico é uma liminaridade que restitui emoções a pessoas, recoloca as problemáticas das relações de poder no campo do social e acentua as insuficiências que constituem o modelo neoliberal quando tenta forjar uma ontologia da pessoa. Mas, quais horizontes alternativos e "imaginabilidades" teríamos em contraposição à lógica do hiperindividualismo?

Outras elaborações e modos de atenção podem ganhar o cenário das medidas em tempos de pandemia. Ailton Krenak (2018) mostra que todo o esforço que encara no movimento indígena não reapresenta uma atenção somente em seu nome, mas chama todas as experiências de sua parentela e incorpora outros povos que "nasceram da terra" às lutas, pois a pessoa só pode existir nas relações com os parentes, com os não-indígenas, com os seres celestes, com a terra, com o Estado, com a diferença, e assim por diante. Porque "sacar uma biografia de um ambiente desses é uma maneira de iluminar todo esse ambiente e projetar sentido na vida de todo mundo; nossos avós, tios, pais, dos nossos irmãos, dos colegas de infância" atenta Krenak. E prossegue: "é uma nave. É uma constelação de seres que estão viajando e transitando no mundo [...] dos seres que vivem e experimentam constante insegurança” (2018, p.5).

Um dos modos de prosseguirmos diante do vírus é recuperar a atenção que não está na chave dual indivíduo versus. sociedade (também aos moldes neoliberais), mas sim nas direções que compreendem as ontologias dos povos indígenas onde as coisas no mundo são feitas nas relações: nas vidas múltiplas que se coabitam e vão se constituindo. A "nave" de Krenak anima considerações de um mundo dilatado, onde pessoas crescem no movimento de partilha de experiências, no qual a posse ocidental dá lugar à "potência do sujeito coletivo". Friccionar essa ontologia junto das políticas públicas e regimes governamentais é capaz de acentuar as assimetrias, projetar medidas diante delas e questionar o modelo de vida do capitalismo (e dos impérios) que colapsou e que dia a dia produz mais mortes.

Em relato sobre a condição dos povos indígenas frente à pandemia, Chirley Pankará (2020), aponta que os anciões e as anciãs são as principais vítimas do vírus da COVID-19 e que muitos já foram vitimados pela doença em diversos territórios indígenas pelo Brasil. Reafirma também que os mais velhos são centrais na transmissão de saberes via oralidade, evidenciando assim a relação entre o conhecimento e a "fabricação" de pessoas nos mundos indígenas. Pankará (2020) diz: "quando um deles morre, seca uma fonte da sabedoria. Nossos 
rios choram, nossas árvores se entristecem". E segue: "cada membro da comunidade sente muito essas perdas. Cada ancião e anciã representa a resistência viva dos povos e são transmissores dos saberes sobre as lutas, o mundo e as cosmologias" ( $/ \mathrm{p}$ ).

A convocação dos anciões e das anciãs feita por Pankará coloca em suspensão o próprio modelo de "indivíduo", pois aqui temos uma direção que anima uma série de relações entre humanos e não-humanos para incitar qualquer apontamento no ínterim da pandemia. Emerge desse sentido linhas de vida que são incansavelmente apagadas por certa lógica que, com veemência, corta e invisibiliza as relações no mundo.

Em uma direção próxima, também concebendo reflexões diante da pandemia, Sandra Benites (2020) demonstra que descobrir uma vacina para um vírus não é a única via para "curar" pessoas. Para isso a autora faz uma diferenciação entre os povos indígenas e os nãoindígenas para explicar as doenças. Se para os Guarani Nhandewa existe uma sistemática entabulação de falas na casa de reza e em reuniões ("encontros de conversa") tratando dos problemas ("delírios" e "pirações") para que eles não "explodam”, já para os brancos os cuidados são realizados apenas quando algo dói e/ou está em um estágio muito avançado. Corroborando com as ponderações de Krenak e Pankará, acredito que Benites também esteja trazendo de volta à vida (especificamente para o "mundo dos brancos") as relações, pois pessoas, doenças, espíritos, florestas, cantos, etc., estão emaranhados nas linhas da própria vida e não há possibilidade de colocá-los em redomas ou ajustá-los em "unidades discretas" (para usar uma orientação de Strathern [2014]).

Manifestando sua inconformação perante as brutalidades e as desmedidas dos brancos, Benites (2020, s/p) exclama: “[n]ão consigo entender a lógica dos djurua kuery quando tratam da doença sem entender que o caminho do bem-estar no mundo inclui humanos e não humanos em volta”.

Ora, o afinco da argumentação de Pankará e Benites em tomar o atual contexto pandêmico junto do "fazer" pessoa (a ontologia da pessoa indígena) em ontologias indígenas é uma direção de contraposição à lógica que desfaz e destrói essas mesmas formas de estar no mundo. As linhas de vida encaradas pelas autoras - saberes, cosmologias, os mais velhos e as mais velhas, doenças, cantos e rezas, humanos e não-humanos, resistências e lutas, caminhos, e assim vai - tecem movimentos alternativos à face voraz que aniquila todo tipo insurgência e imaginação que não são as mesmas impregnadas em duras e deletérias ações de um empreendimento de poder que segue matador.

\section{Considerações Finais}

Uma das sugestões presentes em "O nome do medo" - no sentido de reestabelecer as relações estruturais e históricas às emoções - quando friccionadas às reflexões de intelectuais indígenas - que atuam, entre outras coisas, na ontologia da pessoa indígena - acolhem uma série de lacunas que devem ser levadas em consideração para tratar sobre as questões desses tempos. A propósito, "tratar" sobre esses tempos esboça uma solicitação para que tenhamos uma orientação que desprende um exaustivo encontro com questões do passado (colonial), 
as quais são intensificadas no presente e que devem ser atendidas, para que então possamos sonhar com um futuro possível. Neste sentido, tais considerações - das reflexões artísticas e indígenas que trouxe até aqui - estão a todo o momento costurando - às vezes, literalmente, como é o caso das capas e os medos - e trazendo renovações às demandas vigentes e, ao mesmo tempo, imaginando àquilo que está por vir. Acredito assim que em pandemia é no movimento de crítica e na "imaginabilidade" que reside também uma das tarefas da disciplina antropológica.

Os medos nessa abordagem relacional evidenciam ainda mais as vulnerabilidades e as precariedades estruturais que atingem brutalmente populações que, historicamente, estão mais expostas à morte. Mostram, ainda, que o modelo que recorre ao hiperindividualismo, negligenciando questões históricas e estruturais, não é capaz de promover soluções que atendam às diferenças de modo amplo e com a devida justiça social. Dessa maneira, em tempos pandêmicos, as reflexões indígenas e àquelas produzidas em arte, conciliadas à antropologia, são fundamentais para recobrir as questões das desigualdades geopolíticas, raciais, de gênero e de classe. Uma política neste contexto só será eficaz quando levar a sério essas questões e estimular medidas para compreendê-las e atendê-las. Por fim, que tenhamos a "nave" mobilizada por Krenak como um horizonte a ser seguido e que ela possa endereçar renovações para esses tempos.

\section{Referências bibliográficas}

BENITES, Sandra. (2020). Piração - Corpos que Falam: um lugar para as vozes de estudantes de pós-graduação em quarentena (on-line). Museu Nacional: Rio de Janeiro. Disponível em: https://corposquefalam.weebly.com/escritas/piracao-sandra-benites-ppgasmnufrj

Acesso em: 02 de setembro de 2020.

BUTLER, Judith. (2010). Problemas de gênero: feminismo e subversão da identidade. 3. ed. Rio de Janeiro: Civilização Brasileira.

BUTLER, Judith. (2018). Corpos em aliança e a politica das ruas. São Paulo: Civilização Brasileira.

FLOOD, Richard; NEUENSCHWANDER, Rivane; HERKENHOFF, Paulo; RAYMOND, Yasmil; THOMAS, Rachael; LARSEN, Lars Bang. (2010). Um dia como outro qualquer. Rio de Janeiro: Cobogó; New York: New Museum of Contemporary Art.

KRENAK, Ailton. (2018). A potência do sujeito coletivo - Parte I. Revista Periferias. Rio de Janeiro, n. 2, vol. 2. Disponível em: http://revistaperiferias.org/materia/a-potencia-dosujeito-coletivo-parte-i/ Acesso em: 16 de abril de 2020.

LAGNADO, Lisette (Org). (2017). O nome do medo. Rio de Janeiro: Museu de Arte do Rio; Instituto Odeon.

MBEMBE, Achille. (2018). Necropolítica: biopoder, soberania, estado de exceção, politica da morte. Traduzido por Renata Santini. São Paulo: N-1 Edições. 
NEUENSCHWANDER, Rivane; LAGNADO, Lisette. (2017). Em diálogo. In: LAGNADO, Lisette (org). 2017. O nome do medo. Rio de Janeiro: Museu de Arte do Rio; Instituto Odeon.

PANKARÁ, Chirley. (2020). "Covid-19 e o impacto nas populações indígenas. Povos indígenas frente à covid-19”. Universidade de São Paulo: São Paulo. Disponível em: https://amerindios.wixsite.com/acao/artivos-e-textos Acesso em: 02 de setembro de 2020.

PEDROSA, Adriano. (2014). Rivane Neuenschwander: mal-entendidos. São Paulo: Museu de Arte Moderna de São Paulo.

SAFATLE, Vladimir. (2015) O circuito dos afetos: Corpos políticos, desamparo e o fim do indivíduo. Belo Horizonte: Autêntica.

STRATHERN, Marilyn. (2014). “O conceito de sociedade está teoricamente obsoleto?”. In: STRATHERN, Marilyn. O efeito etnográfico e outros ensaios. Tradução de Iracema Dulley, Jamille Pinheiro e Luísa Valentini. São Paulo: Cosac \& Naify.

\section{sobre o autor}

\begin{abstract}
Alberto Luiz de Andrade Neto
Doutorando em Antropologia Social pelo Programa de Pósgraduação em Antropologia Social da Universidade Federal de Santa Catarina (PPGAS/UFSC). Mestre em Antropologia Social (PPGAS/UFSC) e bacharel em Museologia (UFSC).
\end{abstract}

Recebido em 09/05/2020 Aceito para publicação em 15/09/2020 